\title{
Stigma and its Assessment Methods
}

\author{
Nelson Chan \\ School of Construction, Property \& Planning \\ College of Law \& Business \\ University of Western Sydney
}

Phone: +6129852 4212

Fax: $\quad+61298524185$

E-mail: n.chan@uws.edu.au

\begin{abstract}
This paper discusses the nature of stigma and its assessment methods. Stigma is a value loss to property value due to the presence of a risk perception-driven market resistance. Apart from affecting a contaminated or potentially contaminated property, stigma also affects the value of properties that are not contaminated but are in close proximity to a source of contamination.
\end{abstract}

Although Australia is generally regarded as a clean country, however, there is also contaminated land in this beautiful country. This paper finds that stigma also exists in Australia. Since stigma is caused by risk perception, its impact on property value is difficult to quantify and market evidence cannot be used as a reliable means to assess value loss due to stigma. Regarding stigma assessment methods, this paper looks at the methods suggested by property researchers as well as those used by practising valuers. It also provides a comparison of methods used by Australian valuers and valuers in the US, UK and New Zealand.

The paper finds that the methods suggested by property researchers and the methods used by Australian valuers are not satisfactory. There is a need to research for a better method to assess stigma.

Key words

Stigma, evaluation criteria, quantifying stigma, Australian and overseas methods

\section{Introduction}

In the eyes of a valuer, a contaminated property is no different from an ordinary property except that the property is polluted by one or more hazardous substances. The fact that the property is contaminated requires a valuer to have a thorough understanding of land contamination issues including regulations under relevant environmental laws, the nature of contamination on land, the type of remediation required, and the market condition, etc. As far as valuation is concerned, the main difficulty is the lack of accessible data (Patchin 1988, Spencer 1993, Syms 1996b). A number of methods, including conventional methods like direct comparison method and capitalisation method, and alternative methods such as environmental balance sheet method (Wilson 1992), survey method (Greenberg \& Huges 1993, McLean \& Mundy 1998), multiple regression analysis (Dotzour 1997, Reichert 1997), option pricing method (Lentz \& Tse 1995), mortgage-equity analysis (Chalmers \& Jackson 1996), Monte Carlo Simulation method (Weber 1997), and expected utility method (Wiltshaw 1996), etc. have been introduced to value contaminated land. However, none of these methods are specifically for the assessment of stigma 
It is well known that the value of a contaminated property may be affected by stigma. If the property is not affected by stigma, the valuation is more straightforward as no value adjustment is required in this regard. Where there is evidence to show the existence of stigma, valuers need to take the stigma impact into account. Unfortunately, it is very difficult to quantify stigma. This paper examines the current methods to assess stigma and comment on their robustness.

\section{What is stigma?}

Stigma has many definitions. For example, Dybvig (1992 p.47) defines it as "a market imposed penalty that can affect a property that is known or suspected to be contaminated, property that was once contaminated but is now considered clean, or a never contaminated property located in proximity to a contaminated property." In Australia, the Australian Property Institute (API 1999 p. 190) defines it as "an intangible factor that may not be measurable in terms of cost to cure but may have real impact on market value. It arises from the effect of present or past contamination upon the market's perception of the property and represents a discount, beyond the direct and indirect costs likely to be incurred, required to compensate for the risks associated with contaminated or previously contaminated property". For the purpose $f$ this paper, stigma is defined as "the detrimental impact on property value due to the presence of a risk perceptiondriven market resistance".

A number of property researchers, such as Patchin (1988, 1991 \& 1994), Mundy (1992a, 1992b, \& 1992c), Wilson (1994), Roddewig (1996), Sanders (1996), Syms (1996a, 1997a, \& 1997b), Neustein and Bell (1998), and Bond (2000), etc. have studied and confirmed the impact of stigma on the value of contaminated property. Stigma may have an impact on contaminated land value before, during or after the clean up process (Roddewig 1996). Moreover, it is well accepted that stigma may also affect properties within close proximity to the contaminated land. Regarding the question if stigma is rational or irrational, Wilson (1992) comments that it is inappropriate to make the assumption because value is not dependent on whether the market is rational or irrational.

Today, the awareness of environmental problems is increasing. Very often the public perceives that many risks around them are getting more severe even though there is no scientific evidence to support the suspicion. To a certain extent, the public's perceptions are simply at variance with the real risks (Freudenburg 1988). Stigma, like other environmental issues, arises from the environment risks perceived by the public or the market. Although there may not be sufficient scientific evidence to show that a contaminated property causes any real environmental risks, the perception of potential problems nevertheless causes concerns and anxieties among potential purchasers, occupiers, developers, and financiers, etc. Apart from environmental risks, they also worry about the likely future financial and legal liabilities. It follows that if there is a choice, they will prefer a clean property. The concern and anxiety have led to a market resistance against contaminated or previously contaminated properties (Neustein and Bell 1998). There are a number of researches in this area. A particularly good analysis of the relationship between perceived risks and stigma can be found in Syms (1997a).

The market resistance peaks when people first know about the land contamination and little information about the associated environmental risks is available. Also the incident may be under substantial media exposure such that people may have an unwarranted bad impression of the property. As time lapses and that more information is available about the extent of the environmental risks and the remediation actions taken or to be taken, the concerns and anxieties will ease and the market resistance will diminish (Chalmers \& Jackson 1996). On the other hand, the marketability of the property will be increasing. A classic example given in American texts is that, in the 1970s, there had been great concern about the health risks caused by asbestos. Properties with components made of asbestos were difficult to sell or let. Today, 
when people know more about asbestos and its associated health risks, the concern has been considerably reduced. What was difficult to sell or let before has a much higher marketability today. The change of market resistance and marketability of a contaminated property can be seen in Figure 1 on the next page.

It is evident that market resistance to and marketability of a contaminated property change with the property's position along the time-line. When assessing stigma impact, a valuer is therefore required to identify at which point on the time-line that the valuation is being carried out. At the same time, the valuer has also to consider other relevant criteria to evaluate the magnitude of the stigma. In the USA, Patchin (1991) has identified 5 criteria to evaluate stigma:

1. Fear of hidden clean up costs - fear of insufficient clean up today and future clean up is required.

2. The trouble factor - although the cost of clean up has been allowed for, buyers still feel it necessary to have compensation for the trouble of making the necessary improvement to the property.

3. Fear of public liability - there may be future legal liability even though the property has been cleaned up to the current standards.

4. Lack of mortgageability - inability to get financing for sale or future development of the property.

5. How clean is clean - the remediation standard required and achieved in the cle an up

Further to Patchin's work, Mundy (1992a) also puts forward another 7 criteria to determine the degree of stigma:

1. Disruption - whether the day-to-day business on the contaminated premises is affected.

2. Concealability - can the pollution be seen, smelled or felt?

3. Aesthetic effect - does the contamination visually alter the environment?

4. Responsibility - who is the polluter?

5. Prognosis - the severity and persistence of the contamination.

6. Degree of peril - impact on the entire environment and human health.

7. Level of fear - the degree of people's fearful feeling towards the contamination.

These criteria are accepted and referred to by researchers such as Guntermann (1995), Dotzour (1997), and Syms (1997b) in their study of contaminated land issues. 
Figure 1 Time-line of market resistance and marketability of contaminated land

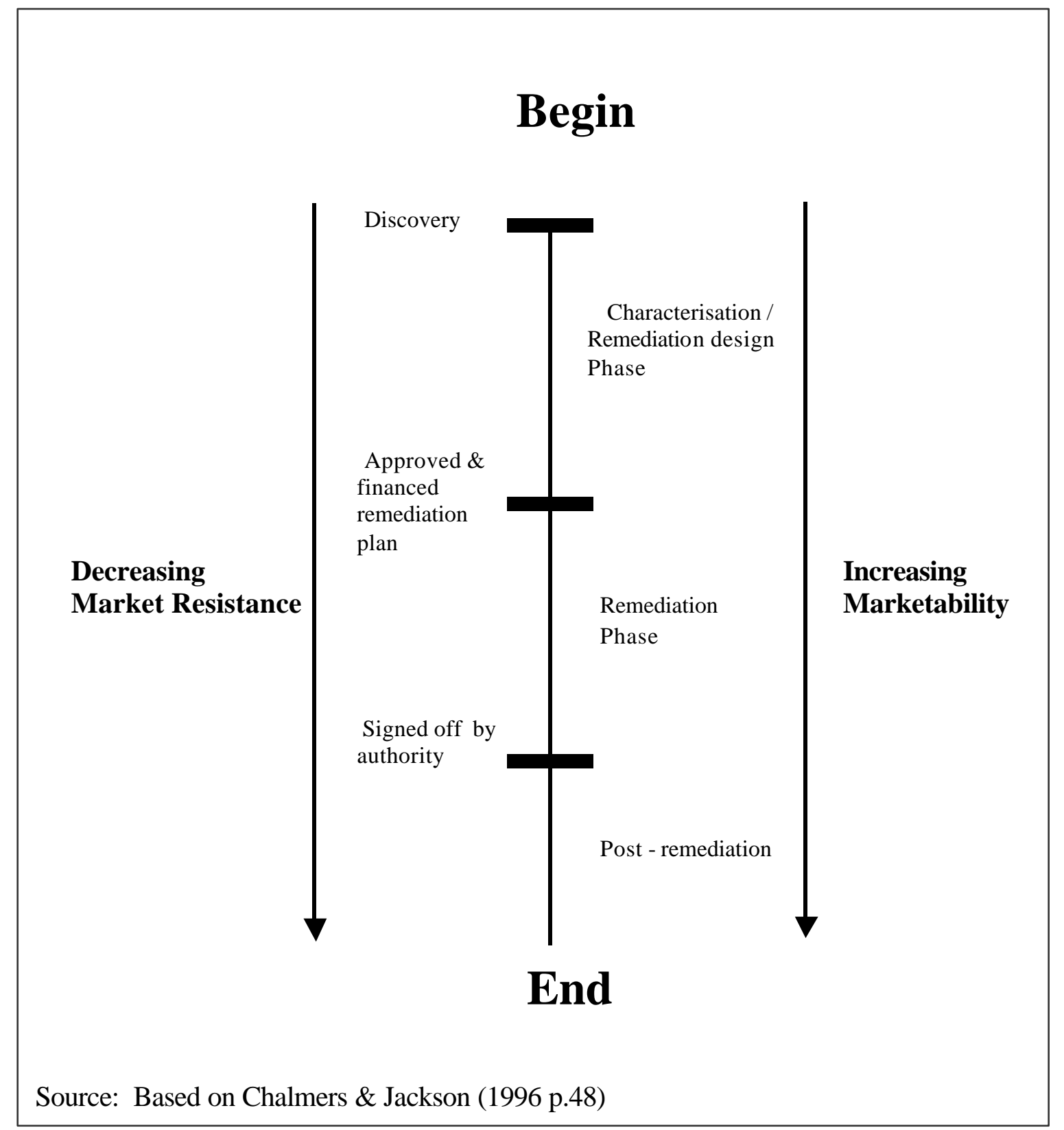

\section{Does Stigma exist in Australia?}

The existence of stigma has been reported in numerous property researches overseas (such as Patchin 1988, 1991 \& 1994, Mundy 1992a, 1992b, \& 1992c, Wilson 1994, Roddewig 1996, Sanders 1996, Syms 1996a, 1997a, \& 1997b, and Neustein and Bell 1998). In Australia, there is also evidence of its existence. In 1998, I conducted a survey of 500 valuers in New South Wales, Victoria and Queensland, with a response rate of $21 \%$ (Chan 2000). The majority of respondents with experience in valuing contaminated land confirm the existence of stigma and that they have allowed for stigma impact in their valuation (see Section 4.5 below for details).

The presence of stigma depends on a number of factors. One of them is the market condition as highlighted in the following case study: 


\section{Case study - Garden Square, Upper Mount Gravatt, Queensland}

The property is a landscaped office park about $12 \mathrm{~km}$ south east of the Brisbane CBD. It has 4 office blocks with a total lettable area of $12,782 \mathrm{~m}^{2}$. As at December 1997, the property was $98 \%$ let. The major tenants included Coles Myer, the Queensland State Government and the Commonwealth Government. The property was built in 1984. In late 1997, the owner entered into an agreement with a property fund (the purchaser) for the sale of the property at $\$ 20.6$ million. In the due diligence process carried out

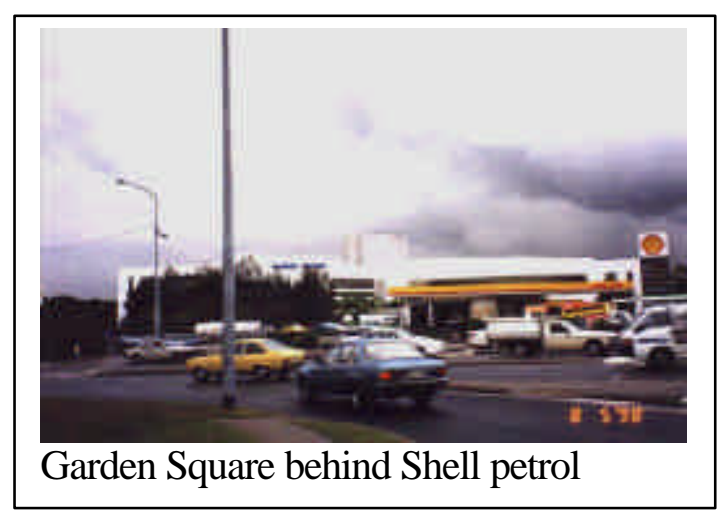
by the purchaser, some contamination was discovered on the site. Further investigation showed that the contaminant was old, weathered fuel which leaked from the adjoining Shell petrol filling station. The contamination was present to both the soil and ground water. The analytical results showed that a very thin plume (30m across) had occurred reaching approximately $70 \mathrm{~m}$ into the subject property. The major health risk problem would be the result of hydrocarbon vapours entering the basement or utilities of the property.

Shell did not deny responsibility and in fact agreed to bear the clean up costs. The purchaser still felt uncomfortable and requested adjustment to the sale price to reflect the stigma factor. Eventually four independent valuers, two from each side, were appointed to assess the stigma impact. The two valuers for the vendor did not find any value loss due to stigma. One of the purchaser's valuers had very different findings. One found no stigma value loss but the other one found that there was a stigma value loss of $\$ 800,000$. Eventually, the vendor and the purchaser settled on a stigma value loss of $\$ 100,000$ and concluded the deal accordingly (Clarke 1998). The case clearly demonstrates that the market condition is a major criterion for the determination of stigma. If it is a buyer's market, stigma may be used as a bargaining chip to negotiate for the final price.

The latest research on stigma in Australia has been carried out by Bond (2000). She carried out a study of 409 residential vacant land sales in Perth between 1992 and 1998. The land concerned was formerly filled with wastes that contain nitrate, arsenic and cyanide. After remediation, the land was subdivided into residential lots. She found that "a site with a history of contamination has a negative impact on value. This 'stigma' effect results in an approximately 35\% decrease in sales price of post-remediated residential sites" (Bond $2000 \mathrm{p}$. $18)$.

Despite the stigma incidents referred to above, it should be noted that not all contaminated land has stigma. Important factors such as the type of contaminants, the degree of contamination, the remediation method, the clean up standards achieved, time lapse between discovery and valuation, who was the polluter/owner, and the market condition, etc. should be considered. In Sydney, the Pulpit Point residential development at Hunters Hill was built in 1992 on a previous oil

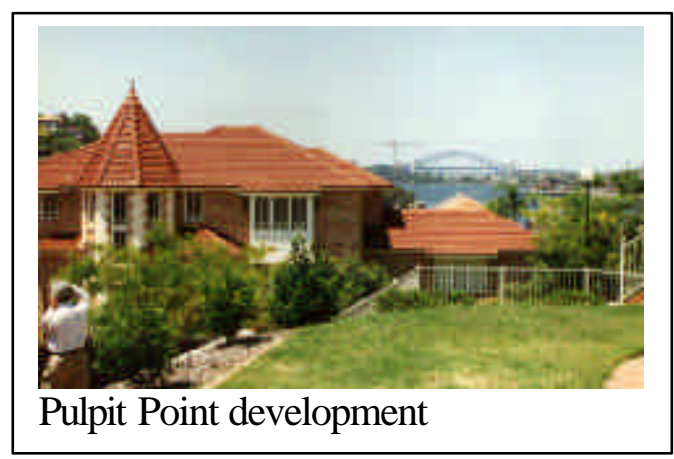


depot site. The site has good water front view and is facing the Harbour Bridge. The oil company spent approximately A $\$ 14$ million to clean up the 12 ha site and sold it for an upmarket residential development. Owing to factors such as the site had been cleaned up by the oil company, and the superior location of the site, etc., the finished houses were sold at premium prices without any stigma impact even in a generally stagnant market. This case demonstrates that who cleaned up the site and the physical site characteristics are important criteria in the determination of stigma impact. In addition, the 'deep pocket' principle may also have an important

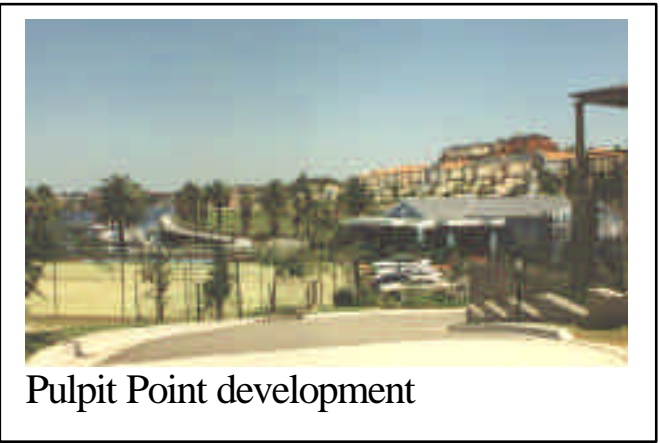
role to play in this case.

\section{How to quantify stigma? - The researchers' approaches}

\subsection{Where market data is available}

In my 1998 survey, it was found that the majority of Australian valuers had used the impaired value approach to value contaminated land. The impaired value approach can be represented by equation below:

$$
\mathrm{V}_{\mathrm{c}}=\mathrm{V}_{\mathrm{u}}-\mathrm{L}-\mathrm{C}_{\mathrm{r}}-\mathrm{S} \quad \text { Equation } 1
$$

where: $V_{c}=$ contaminated value,

$\mathrm{V}_{\mathrm{u}}=$ uncontaminated value,

$\mathrm{L}=$ loss due to reduced income/productivity and/or le gal liabilities,

$\mathrm{C}_{\mathrm{r}}=$ investigation, remediation and monitoring costs,

$\mathrm{S}$ = stigma impacts

The impaired value approach outlined earlier is a logical model for valuing contaminated land. However, it requires valuers to explicitly consider the stigma impact. It is this requirement that causes problem. How should stigma be quantified?

Mundy (1992a) suggests that in a perfect world where there is a good quality set of market data, stigma can be determined using a direct approach having regard to rent, occupancy, expenses and capitalisation rate. Chalmers and Roehr (1993) support this idea and demonstrate the valuation of a contaminated property with the capitalisation method and show how the yield premium, $\mathrm{i}_{c}$, (the stigma value reduction discount rate) can be identified. They also show that the yield premium will change with the lapse of time and have a pattern as shown in Figure 2 on the following page. 
Figure 2 Variation of yield premium

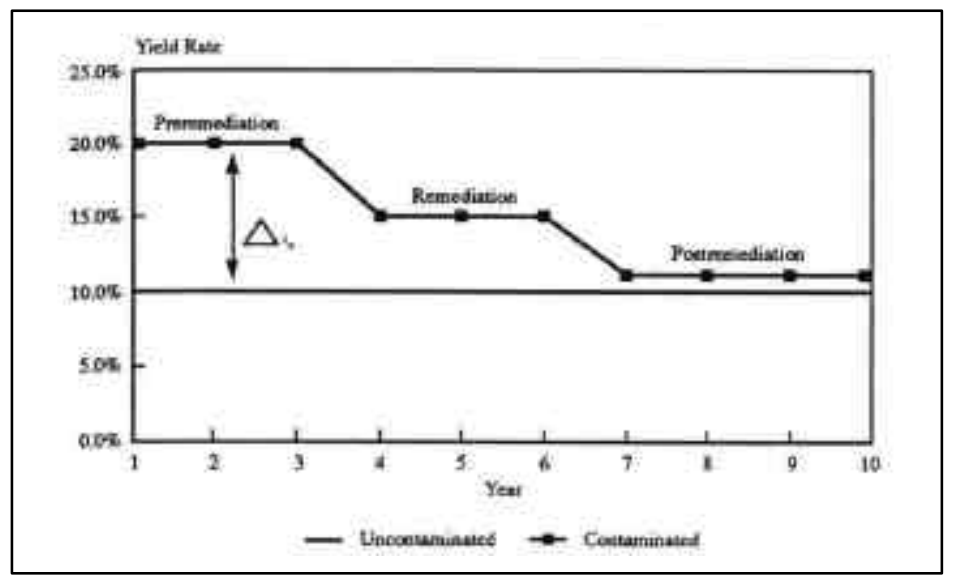

Source: Chalmers \& Roehr 1993 p.35

Patchin (1994) also shows that stigma may be assessed with the direct comparison method. He suggests that the unimpaired and impaired values of the property are to be assessed using the direct comparison method. The indicated stigma is estimated by subtracting the impaired value from the unimpaired value. He also suggests estimating the indicated stigma by subtracting the actual selling price from the unimpaired value. A similar yet more elaborate approach is also put forward by Syms (1996a \& 1997b). Apart from having reference to the nature and extent of contamination of comparable properties, it also takes into consideration the present value of remediation costs. This approach again has been borrowed and put into the Professional Practice 2000 by the API. An example of this method is reproduced in Figure 3 on the next page.

These two approaches, however, have problems. Firstly, as mentioned before, it is difficult to get the unimpaired value by direct comparison because of the uniqueness of individual contaminated property. Two properties may be physically similar in all aspects but it is very rare that they are contaminated by the same type of contaminants and subject to the same degree of contamination. Secondly, it can be seen from Equation 1 that the difference between the unimpaired and impaired values is more than just the value loss due to stigma. Even if the expected repair cost (remediation cost) is added to the sale price (the impaired value), Sanders (1996 p.61) points out that it will not necessarily "give a good read on residual stigma".

Recently, Roddewig (2000) has suggested the use of an environmental risk scoring system to assess stigma. It is based on analysing case studies (sales of comparable contaminated properties) and assigning a score to source/cause of risk/stigma of the comparable properties and the subject property respectively. He suggests to assign a score of $0-3$ for low level of risk, $4-6$ medium level of risk and $7-9$ for high level of risk. By comparing the total score of the subject property to those of the case studies, the valuer may determine the stigma adjustment percentage for the subject property. He claims that this method may give more precision in assessing a stigma adjustment factor. This method relies on the availability of data from comparable contaminated properties. Unfortunately, it is very rare to get true comparables because of the uniqueness of individual contaminated properties. Accordingly its application is limited. 
Figure 3 Syms's enhanced stigma assessment method

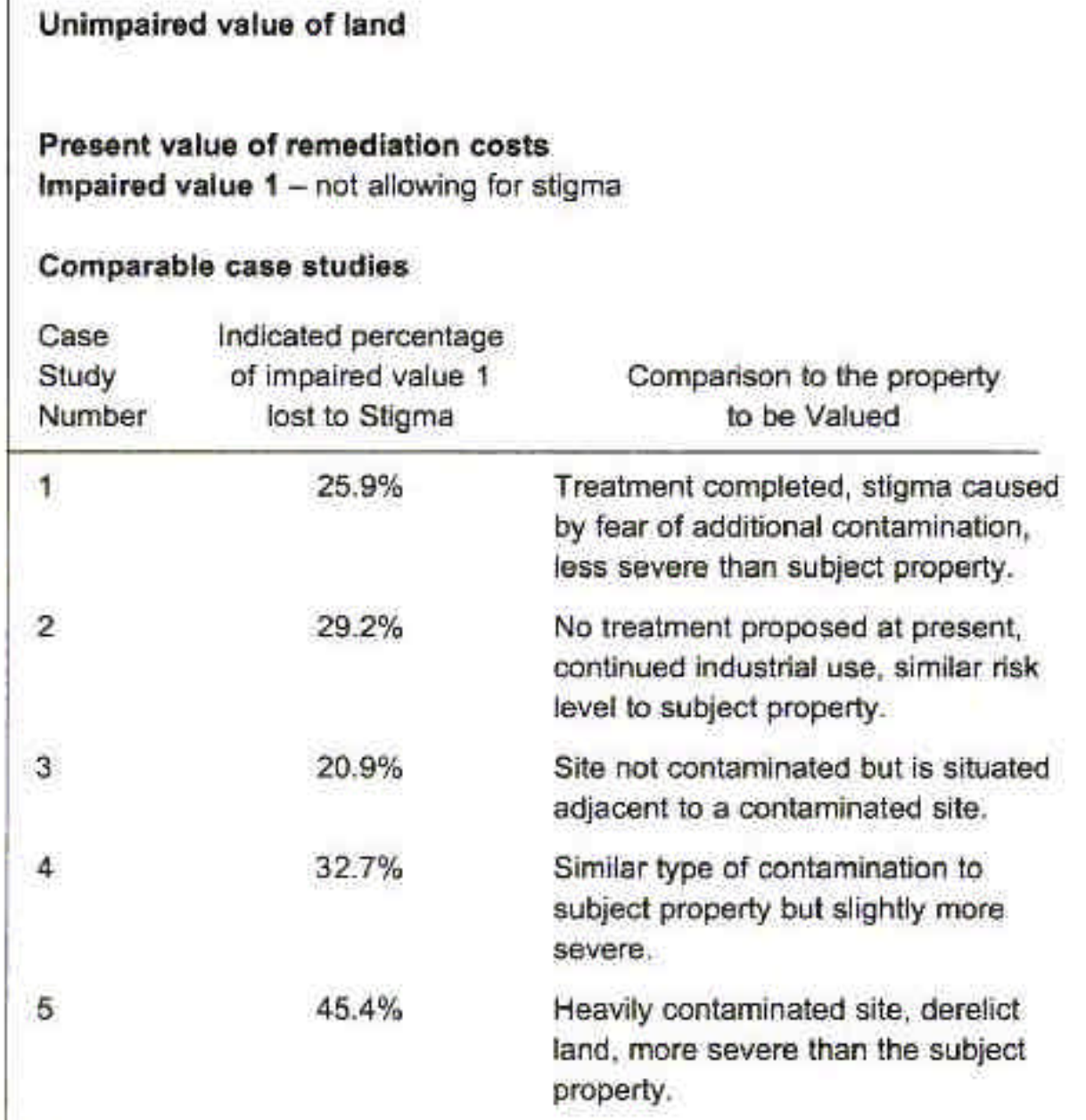

Range of stigma effects indicated by comparables $20.9 \%$ to $45.4 \%$

Comparables closest to subject property; numbers 2 and $4,29.2 \%$ to $32.7 \%$

Therefore percentage stigma applicable to the subject property is $31 \%$

Amount of stigma @ $31 \%$ of impaired value 1

Impaired value 2

$£ 960280$

(taking account of treatment and associated costs and stigma)

Add value of buildings from Box 9.5

$£ 1000000$

Total value of asset

say

$\$ 1960000$

Percentage reduction in value attributable to contamination

$21.60 \%$

Source: Syms (1997b, p.190)

\subsection{Where market data is unavailable}

In the absence of the required set of market data, Mundy (1992a) suggests that stigma can be quantified by the application of contingent valuation method and trade-off (conjoint) analysis method. Mundy's suggestions have the support of researchers such as Chalmers \& Roehr (1993), Greenberg \& Hughes (1993). However, in a subsequent study (Mclean \& Mundy 1998), despite finding that the contingent valuation method is the most defensible one, Mundy and his 
co-author had reservations and recommended using this method as a supplement only. It can be seen that it is still premature to apply these methods for day to day operation of a valuer.

Syms (1997b) introduces a risk assessment model to assess stigma where market data is not available. The model applies the "professional perceptions which influence the judgements the valuer will have to make in order to arrive at his or her opinion of value" (Syms 1997b p 198). The model consists of 5 sets of data. It does not rely on market evidence but instead is based on 26 industrial activities identified by Syms and a stigma value reduction range of $21 \%-69 \%$ taken from the work of Patchin (1994). It uses a survey of valuers and developers of contaminated properties to state the perceived impact on value before redevelopment; the perceived post-remediation impact on value; and the perceived impact on value after remediation/redevelopment. A sample of the model is reproduced at Figure 4 on the next page.

In the model, the first set of data is the observed stigma effect $(21 \%-69 \%)$ which sets a baseline for stigma impact on property value. The second set of data is the perception of relative levels of risk of 26 selected industrial activities and ranked according to the perceived stigma effect. These two sets of data provide a framework for assessing the target contaminated land. The remaining three data sets are based on risk related data for the present and expected condition of the subject contaminated land. To apply the model, a valuer needs to obtain "value adjusters' from data set two to five. A mean value is calculated using the 'value adjuster' figures. The mean value obtained is the stigma factor required for the valuation.

This model is an improvement over the earlier methods, but can go further. The model is partly based on the stigma value reduction range from Patchin's work in the US, it may not reflect the real life conditions in the UK. Regarding the 26 selected industrial activities, they are far from complete. In the real world, there are more than 26 industries and land uses that may have land contamination problems. For example in Australia, the Australian Property Institute's Professional Practice 2000 lists 67 problematic industries and land uses. Yet this list is still not exhaustive. Bond (2000) also questions the validity of the suggestion to take the average of the 'value adjusters' in this regard. Since 'value adjusters' reflect different characteristics of the property, the different stage of the redevelopment process and the remediation method, the averaging approach appears to be inappropriate. Also if the 'value adjusters' vary widely, the accuracy of the mean value is questionable. 
Figure 4 Syms's Risk Assessment Model

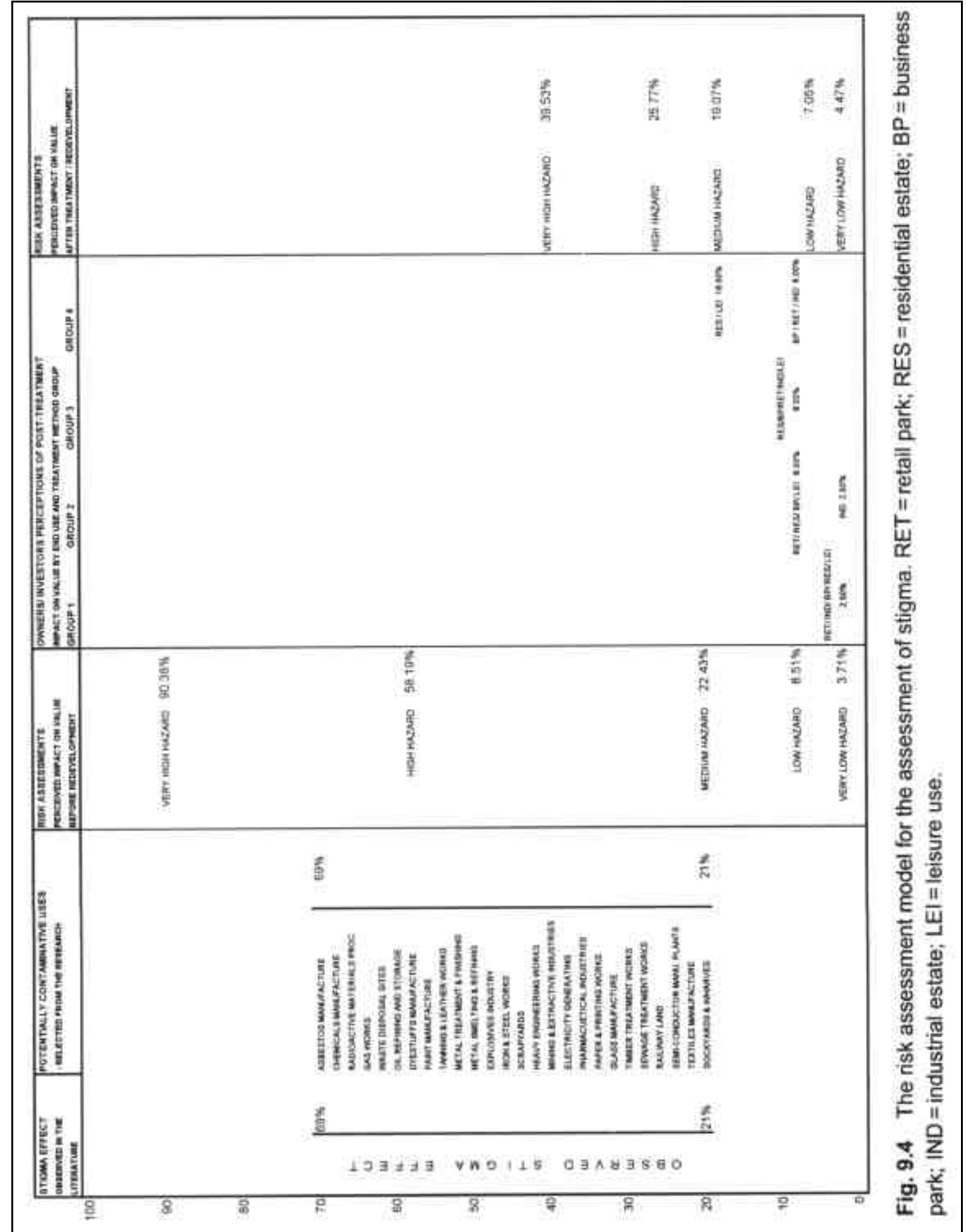

Source: Syms (1997b, p.200) 


\subsection{Methods used by practitioners}

In my 1998 survey of Australian valuers (Chan 2000), a large number of respondents claimed they had considered stigma when performing valuation of contaminated property. Table 1 below shows their attitude towards stigma, $48 \%$ of the less experienced respondents claimed that their clients had concern for this value impact, with $56 \%$ of the experienced respondents shared the same view. It appears that the stigma issue has already caused a significant concern, if not an alarm, among clients in the three states. This finding coincides with the finding of Schwaiger (1993) that $92 \%$ of the banks surveyed (18 Australian banks) are either concerned or very concerned about their liability under the current environmental legislation.

Table 1 Stigma factor issues

\begin{tabular}{|lc|c|c|}
\hline Questions & $\begin{array}{c}\text { Less experienced } \\
\text { group (\%) }\end{array}$ & $\begin{array}{c}\text { Experienced } \\
\text { group (\%) }\end{array}$ \\
\hline Clients concern for stigma impact? & (Yes) & 48 & 56 \\
\hline Allowance for stigma factor in valuation? (Yes) & 58 & 72 \\
\hline
\end{tabular}

Table 1 also shows that a significant number of respondents, $58 \%$ and $72 \%$ respectively, had made allowance for the stigma factor in their valuations. This may imply that the majority of contaminated properties valued have stigma impact. Valuers realise the seriousness of the issues and have taken appropriate action to carry out valuations.

Regarding the stigma assessment methods, the respondents claimed to have applied various approaches for this purpose, see Table 2 below. Although a number of respondents had chosen not to express their views, the figures nevertheless showed that the majority of respondents used increased discount rate and percentage adjustment methods to allow for stigma impacts. The lump sum adjustment method had the least support.

Table 2 Stigma adjustment approaches:

\begin{tabular}{|l|c|c|c|}
\hline \multicolumn{1}{|c|}{ Questions } & $\begin{array}{l}\text { Less } \\
\text { experienced } \\
\text { group (\%) }\end{array}$ & $\begin{array}{l}\text { Experienced } \\
\text { group (\%) }\end{array}$ & $\begin{array}{l}\text { Out of total } \\
\text { respondents with } \\
\text { experience } \\
\text { (\%) }\end{array}$ \\
\hline Increased discount rate & 16 & 22 & 19 \\
\hline Percentage adjustment & 29 & 28 & 29 \\
\hline Lump sum adjustment & 3 & 6 & 5 \\
\hline Other methods & 3 & 13 & 11 \\
\hline $\begin{array}{l}\text { Need to have a dedicated method to } \\
\text { value contaminated land? }\end{array}$ & 10 & 13 & 52 \\
\hline $\begin{array}{l}\text { Willingness to try new method to } \\
\text { value contaminated land? }\end{array}$ & 35 & 69 & 8 (Yes)
\end{tabular}

In similar surveys conducted in the US, UK and New Zealand (Kinnard et al 1999), it was found that $66 \%, 80 \%$ and $83 \%$ of the respondents in the US, UK and New Zealand respectively used increased discount rates for adjustment.

Regarding other methods, the Australian respondents claimed to have used methods such as zero adjustment, arbitrary adjustment, higher profit and risk factor, using comparable evidence, and lower loan to value ratio. In comparison, respondents in the US adopted reduced rental income, increased vacancy rate, increased capitalisation rate, increased debt interest rate, 
reduced loan to value ration, reduced amortisation period, increase equity yield rate and increased equity dividend rate for adjustment. The UK and New Zealand respondents only use reduced income as alternative method for adjustment (Kinnard et al 1999).

It can be seen that at present, there is a lack of a uniform approach to make allowance for stigma in Australia. While each method mentioned above has its own merit, the large number of methods makes it difficult for the valuers to choose the appropriate method to assess stigma. It is interesting to note that despite the lack of a uniform approach, only a small fraction of the respondents consider that there needs to be a specific method to estimate stigma and to value contaminated land. The experienced group is more open: about $70 \%$ of them are willing to try the new method if one is available.

When the respondents were asked about how they arrived at a figure for stigma adjustment with the methods mentioned, they declined to give the details but only said that they had taken all relevant factors into consideration. The response may imply that most of the figures were arrived at arbitrarily or through their 'gut-feeling'.

\section{Conclusion}

Stigma adjustment is a key element in contaminated land valuation when the impaired value approach is used. In Australia, valuers are using methods similar to their overseas counterparts to assess stigma. Despite the presence of a variety of methods, the stigma adjustment factor is generally obtained through a 'guesstimation' or 'gut-feeling' process. It is possible that well experienced valuers may estimate an accurate stigma adjustment factor in this manner. However, the skill is difficult to master and defend. This approach makes it very difficult for valuers who do not have the skill to assess stigma. Further, even the well-experienced valuers need a better method to verify their 'guesstimation'.

The methods suggested by researchers are not much better. Mundy's suggestions are fine in an ideal situation. In the real world, it is very difficult to apply the methods because of the lack of sufficient amount of market data. The contingent valuation method is also not practical because it is a survey-based method. In real life, valuers are working under a very tight schedule. They may be required to submit the valuation report their client within a few days. There is no time to prepare and conduct the survey. The methods suggested by Patchin, Syms and Roddewig are also unsatisfactory for reasons given earlier. Accordingly, there is a need for a better method to assess stigma.

What should the stigma assessment model/method look like? The answer may be found from Trott's comment (1980 cited in Baum \& Crosby 1989 p.128) that "[a] valuation technique, if it is to be accepted by the profession, must be easily understood and easy to use. Its theoretical soundness must be matched by a practical application". This view is also shared by Syms (1997b p.197) in his comment "[a]ny proposed model need to conform, so far as is possible, to the procedures recommended by the surveying profession, otherwise it is unlikely to be accepted by practitioners." These comments will no doubt have a significant impact on the development of an acceptable stigma assessment model. As pointed out on earlier that Patchin and Mundy have identified a number of criteria to determine stigma. It is likely that an acceptable model will be based on a multiple criteria decision making method. 


\section{References}

Australian Property Institute (API) 1999, Guide Note 15, Professional Practice 2000, pp.183 205.

Baum A. \& Crobsy N. 1989 Property Investment Appraisal, Routledge London.

Bond S. G. 2000, Do Market Perceptions Affect Market Prices? A case study of a remediated contaminated site, research paper presented at the $16^{\text {th }}$ American Real Estate Society Conference, Santa Barbara, California, 29 March - 1 April.

Chalmers J.A. \& Jackson T.O. 1996, Risk Factors in the Appraisal of Contaminated Property, The Appraisal Journal, LXIV (1), pp.44 - 58.

Chalmers J.A. \& Roehr S.A. (1993) Issues in the Valuation of Contaminated Property, The Appraisal Journal, LXI (1), pp.28 - 41.

Chan N., 2000, How Australian Appraisers Assess Contaminated Land, The Appraisal Journal, LXVIII (4), pp.432 - 440.

Clarke G.D., Director of McGees National Property Consultants, (interview, August 1998).

Dotzour M. 1997, Groundwater Contamination and Residential Property Values, The Appraisal Journal, LXV (3), pp.279 - 285.

Dybvig L. O. 1992, Contaminated Real Estate Implications for real estate appraisers, The Research And Development Fund, Appraisal Institute Of Canada (AIC).

Freudenburg W.R. 1988, Perceived Risk, Real Risk: Social Science And The Art Of Probabilistic Risk Assessment, Science, 242, pp.44 - 49.

Greenberg M. \& Huges J. 1993, Impact of Hazardous Wastes Sites on Property Value and Land Use: Tax Assessors' Appraisal, The Appraisal Journal, LXI, (1), pp.42 - 51.

Guntermann K.L. 1995, Sanitary Landfills, Stigma and Industrial Land Values, The Journal of Real Estate Research, 10 (5), pp.531 - 542.

Kinnard W.N., Worzala E.M., Bond S. \& Kennedy P. 1999, Comparative Studies of United States, United Kingdom and New Zealand Appraisal Practice: Valuing Contaminated Property. Research paper presented at the $15^{\text {th }}$ American Real Estate Society Annual Meeting in Tampa, Florida, 7 - 10 April.

Lentz G.H. \& Tse K.S.M. 1995, An Option Pricing Approach to the Valuation of Real Estate contaminated with Hazardous Materials, Journal of Real Estate Finance and Economic, 10 (2), pp. $121-144$.

McLean D.G. \& Mundy B. 1998, The Addition of Contingent Valuation and Conjoint Analysis to The Required Body of Knowledge for the Estimation of Environmental Damages, Journal of Real Estate Practice and Education, 1 (1), pp.1 - 19.

Mundy B. 1992a, Stigma and Value, The Appraisal Journal, LX (1), pp.7 - 13.

Mundy B. 1992b, The Impact of Hazardous Materials on Property Value, The Appraisal Journal, LX (2), pp.155 - 162. 
Mundy B. 1992c, The Impact of Hazardous Materials on Property Value: Revisited, The Appraisal Journal, LX (4), pp.463 - 471.

Neustein R.A. \& Bell R. 1998, Diminishing Diminution: A Trend in Environmental Stigma, Environmental Claims Journal, 11 (1), pp. 47- 59.

Patchin P.J. 1988, Valuation of Contaminated Properties, The Appraisal Journal, LVI (1), pp.7 $-16$.

Patchin P.J. 1991, Contaminated Properties - Stigma Revisited, The Appraisal Journal, LIX (2), pp.167 - 172 .

Patchin P.J. 1994, Contaminated Properties and the Sales Comparison Approach, The Appraisal Journal, LXII (3), pp.402 - 409.

Reichert A.K. 1997, Impact of a Toxic Waste Superfund Site on Property Values, The Appraisal Journal, LXV (4), pp.381 - 392.

Roddewig R. 1996, Stigma, Environmental Risk and Property Value: 10 Critical Inquiries, The Appraisal Journal, LXIV (4), pp.375 - 387.

Roddewig R. 2000, Adjusting Environmental Case Study Comparables by Using an Environmental Risk Scoring System, The Appraisal Journal, LXVIII (4), pp.371 - 374.

Sanders M.V. 1996, Post-Repair Diminution in Value from Geotechnical Problems, The Appraisal Journal, LXIV (1), pp.59 - 66.

Spencer J.A. 1993, Standard for Valuation of Contaminated Land in Australia, The Valuer And Land Economist, 32 (8), pp.585 - 587.

Syms P.M. 1996a, Dealing with contaminated assets, Estates Gazette, Issue 9612, pp.124- 125.

Syms P.M. 1996b, The Valuation of Contaminated Land: the Problems Caused by Lack of Accessible Data in the United Kingdom, Journal of Property Development, 1 (1), pp.17 - 25.

Syms P. 1997a, Perceptions of risk in the valuation of contaminated land, Journal of Property Valuation \& Investment, 15 (1), pp.27 - 39.

Syms P. 1997b, Contaminated Land, Blackwell Science.

Weber B.R. 1997, The Valuation of Contaminated Land, Journal of Real Estate Research, 14 (3), pp.379- 398.

Wilson A.R. 1992, Environmentally Impaired Valuation: A Team Approach To a Balance Sheet Presentation, Technical Report: Measuring the Effects of Hazardous Materials Contamination on Real Estate Values: Techniques and Applications, Appraisal Institute, pp.23 - 42.

Wilson A.R. 1994, The Environmental Opinion: Basis for an Impaired Value Opinion, The Appraisal Journal, LXII (3), pp.410 - 423.

Wiltshaw D.G. 1996, An economic analysis of contaminated land, remediation and liability, Journal of Property Research, 13, pp.131 - 141. 